\title{
Hacia el Abra de Punta Corral: movimientos, danzas y elementos naturales en rituales del mundo andino (Noroeste Argentino)
}

\author{
María Fernanda RoDRÍGUEZ \\ Instituto Nacional de Antropología y Pensamiento Latinoamericano \\ (Buenos Aires, Argentina) \\ mfrodriguez18@gmail.com
}

Recibido: 24 de julio de 2013

Aceptado: 4 de septiembre de 2014

\begin{abstract}
RESUMEN
Esta investigación forma parte de un proyecto más amplio acerca del estudio de las danzas, los movimientos y los elementos naturales que integran los rituales y festividades propios del Noroeste argentino a través del tiempo y en distintos ámbitos geográficos. La misma consiste en el análisis del cuerpo en movimiento desde la perspectiva de la antropología del cuerpo, en la Peregrinación al Santuario del Abra de Punta Corral que tiene lugar todos los años desde Tilcara, Provincia de Jujuy. El marco teórico y conceptual adoptado corresponde al paradigma del embodiment inserto en la fenomenología. El objetivo general es determinar las relaciones que se entablan en esta festividad-ritual entre corporalidad, movimiento y poder o empoderamiento, tanto individual como grupal, considerando especialmente las bandas de sikuris que participan. La metodología incluye trabajos de campo que responden a los métodos de la etnografía dentro del marco teórico propuesto. De acuerdo con lo observado y analizado, los movimientos y las danzas, en tanto performance, son la expresión genuina de cada individuo y de los grupos humanos que hacen al papel de actores y grupos sociales, y al mismo tiempo denotan ciertos aspectos de la estructura social, constantes y a la vez variables en tiempo y espacio.
\end{abstract}

Palabras clave: Bandas de sikuris, embodiment, movimiento individual y grupal, mundo andino, Punta Corral, ritual.

\section{Towards Abra de Punta Corral: Movements, Dances and Natural Elements at Andean World Rituals (Northwestern Argentina)}

\begin{abstract}
This research is part of a broader project in relation to dances, movements and natural elements integrated in rituals and festivities at the Argentinean Northwest over time and in different geographical areas. The same one is about the analysis of the moving body, from Body Anthropology perspective, raised in the Pilgrimage to Abra de Punta Corral Sanctuary, which takes place every year from Tilcara, Jujuy Province. The theoretical and conceptual framework adopted is belonging to the Embodiment paradigm insert in Phenomenology. The main objective is to decide in this festivity-ritual the relationships between corporality, movement and power or empowerment, individual as well as collective, especially considering the sikuris bands involved. The methodology includes fieldwork in relation to ethnography methods within the proposed framework. According to observation and analysis, movements and dances performance are the genuine expression of each individual and human groups that make the role of actors and social groups, and also denote, in time and space, several constant and variable social structure aspects.
\end{abstract}

Key words: Sikuri bands, embodiment, individual and group movements, Andean world, Punta Corral, ritual.

Sumario: 1. Introducción. 2. Marco teórico y conceptual. 3. Metodología. 4. La Peregrinación y el ritual. 5. Movimientos grupales, individuales y personales. 6. Discusión y conclusiones. 7. Referencias bibliográficas.

\section{Introducción}

Este trabajo forma parte de una investigación más amplia que propone el estudio de las danzas, los movimientos y los elementos naturales que integran los rituales y las 
festividades propias del Noroeste argentino (NOA) a través del tiempo y en distintos ámbitos geográficos. El mismo consiste en el análisis del cuerpo en movimiento en la Peregrinación al Santuario del Abra de Punta Corral, la cual tiene lugar todos los años desde Tilcara, Provincia de Jujuy, considerando especialmente las bandas de sikuris que participan.

La Peregrinación al santuario del Abra de Punta Corral incluye a la Virgen del Abra, los calvarios, el Cristo del Santuario y el cerro próximo a este último que se incorpora a través de circuitos secundarios. Se trata de un ritual y como tal implica una serie de acciones basadas en creencias y, al mismo tiempo, responde a la necesidad de reforzar dichas creencias. En este sentido, es importante tener en cuenta que no todos los que participan actualmente a la peregrinación lo hacen en función de su religiosidad, ya que también hay quienes van con interés turístico o comercial. No obstante, al analizar el ritual en sí mismo se considera a quienes forman parte de él respondiendo a sus creencias.

En este sentido, Citro (2009a) plantea que durante los rituales tiene lugar la intensificación de las sensaciones y emociones, y vincula el ritual en acción con las relaciones de poder; entonces la resonancia corporal es el estado ritual de apertura perceptiva, mimesis y emoción intensa. De este modo, la performance ritual modifica la materialidad corporal del danzante o de quien se mueve de un modo particular. Csordas (1994) sostiene que el ritual socializa a los performers en determinados modos somáticos de atención constituidos culturalmente, ya que entra aquí en juego la atención hacia el propio cuerpo y hacia el cuerpo de los otros y sus movimientos. Estos cambios en la corporalidad de los participantes, que se vinculan sin duda con la socialización, son los que se intenta recuperar en este trabajo.

Durante la festividad de Semana Santa se realiza la celebración a la Virgen de Copacabana en las localidades de Tilcara, Tumbaya, Tunalito y Maimará. La misma consiste en distintas procesiones que parten de estos pueblos con diferentes destinos: desde Tumbaya y Tunalito se dirigen al Santuario de Punta Corral, mientras que las que parten de Tilcara y Maimará lo hacen hacia el Santuario del Abra de Punta Corral. Es importante conocer esta articulación territorial para considerar las distintas interacciones que incluyen a las diferentes bandas de sikuris en tiempo de Semana Santa. Desde ambos santuarios y durante los días previos al ascenso, los promesantes bajan sus imágenes a las iglesias de las mencionadas localidades (Zanolli et al. 2010). En todos los casos participa un importante número de bandas que adquieren un papel protagónico.

La peregrinación al Abra de Punta Corral ha sido descrita por distintos autores considerando los variados aspectos que la integran, tanto desde una perspectiva antropológica e histórica como etnomusicológica tomando como eje las bandas de sikuris (Cortázar 1965; Lafón 1967; Luján López 2002; Machaca 2004; Moniño 2004; Zanolli et al. 2010, entre otros). Este trabajo pretende dar continuidad a los mencionados estudios desde la mirada que ofrece la antropología del cuerpo.

El origen y los cambios que se sucedieron han sido ya analizados en forma detallada (Machaca 2004; Zanolli et al. 2010), por lo que sólo vamos a hacer mención de los acontecimientos fundadores para facilitar la comprensión del ritual. En este sentido, en el año 1835, más de dos siglos después de que comenzara el culto a Nuestra 
Señora de Copacabana en Bolivia, como se explica en el siguiente acápite, se produjo un hecho considerado «milagro» en el abra de la Estancia grande en Punta Corral, localidad de Tumbaya. Un campesino -Don Pablo Méndez- tuvo la aparición de una señora de cabellera blanca. Al día siguiente, en el sitio que había dejado señalado, encontró una piedrita blanca que le recordó la forma de algunas estampas de la mencionada Virgen de Copacabana. La tomó y se la llevó al sacerdote de Tumbaya, quien advirtió el parecido y decidió que esta piedrita quedara en su Iglesia. Al tiempo la misma desapareció y fue encontrada luego en el lugar en donde se halló por primera vez. Esto se interpretó como el deseo de la Virgen de permanecer allí y por lo tanto se le construyó en ese lugar una capilla, que sería el principal centro de culto (Cortázar 1965; Lafón 1967; Zanolli et al. 2010).

La denominación Copacabana alude a la imagen venerada desde 1583 en el Alto Perú en la zona del lago Titicaca, realizada por un artista del lugar-Francisco Tito Yupanqui- quien la talló en madera de agave a partir del modelo de la Virgen de la Candelaria. Esta última fue consagrada en el año 1559 como Patrona General del archipiélago canario (Zanolli et al. 2010). Es interesante destacar aquí que, al igual que en Europa, la Virgen fue una imagen apropiada para heredar la tradición de las diosas-madres vinculadas con la Madre Tierra, la Luna y en general las divinidades asociadas con la fertilidad. La presencia de la Virgen de Copacabana y la difusión de sus milagros en la población local otorgó continuidad cultural y religiosa en la transición entre el pasado andino y el orden cristiano, permitiendo la permanencia con nuevos significados de la sacralidad del lago Titicaca (Costilla 2010).

Gisbert (1994) sugiere que el culto a Copacabana es muy antiguo y que probablemente esté vinculado con ritos pre-incaicos e incluso aymaras practicados por los uru en relación con las diosas lacustres. Copacabana era considerado una huaca, es decir lugar y elemento de adoración. Allí residían seis ídolos, entre los cuales fue célebre el que llevaba el mismo nombre, reverenciado por los pueblos de las islas y las orillas del lago Titicaca (Machaca 2004). Desde la época incaica tuvieron lugar las peregrinaciones a las islas sagradas del Sol y de la Luna en Bolivia, las cuales implicaban la movilización de grupos humanos desde zonas alejadas. También se llevaban a cabo peregrinaciones a los santuarios de altura en donde se realizaban ofrendas y sacrificios. Por lo tanto, existía una tradición al respecto ya en ese momento (Machaca 2004; Costilla 2010).

Con respecto a la etimología, el término Copacabana aparece ligado a las piedras sagradas, elementos rituales muy importantes en los Andes del Sur. Según la descripción de Ramos Gavilán (1976), el ídolo Copacabana era de piedra azul vistosa y miraba hacia el templo del Sol. En aymara-quechua Copacabana significa «observar el lago, mirador de la piedra preciosa o mirador del azul precioso» (Luján 2002: 196). Es interesante advertir que a la Virgen de Copacabana se le atribuyen milagros en relación con el agua, y el color azul se asocia con las características de su manto. Se destaca especialmente el hecho de que se haya utilizado la antigua expresión -Copacabana- para nombrar a esta Virgen en lugar de la advocación hispana que le dio origen: Virgen de la Candelaria (Costilla 2010). En tiempos virreinales la Virgen fue representada como Madre Tierra en distintas pinturas (Gisbert 1994; Machaca 2004). 


\subsection{Sikus y sikuris}

El siku es un instrumento prehispánico de ejecución colectiva, tradicionalmente interpretado por los hombres. El término siku es quechua y denomina a un tipo de flauta de pan andina que consiste en un aerófono de soplo directo, formado por una serie de tubos cerrados atados en forma de balsa que puede contar con más de una hilera. En la actualidad se encuentra en el Altiplano de Perú y Bolivia, parte de Chile y Argentina y se ejecuta en bandas conformadas por varios pares de integrantes que incluyen el bombo, la huancara y el redoblante. La ejecución del siku implica complementariedad, modalidad denominada «tocar contestado» por los actores sociales que lo ejecutan, debido a la disposición de los sonidos en los sikus que componen la tropa o banda. Por este motivo, la interpretación de una melodía requiere de al menos dos sikuris en colaboración para lograr una unidad (Vega 2012).

Machaca (2004) sostiene que la materia prima para confeccionar los sikus es una caña hueca que crece en diferentes regiones de Bolivia, siendo preferidas las variedades quime, chuqui y songo que crecen en las yungas del Departamento de La Paz, en el Chapare, Departamento de Cochabamba y en otras regiones bajas de Bolivia, tales como Beni, Santa Cruz y Pando. Destaca además que es difícil reemplazar los tubos dañados utilizando cañas de Jujuy, según los datos que le proporcionó un poblador de Tilcara. También señala que los sikus nuevos se ablandan humedeciéndolos con agua de romero, molle u otras hierbas de sabor amargo, igual que en Bolivia. Al romero se le atribuyen propiedades vinculadas con la memoria, lo cual es importante ya que los sikuris deben recordar gran cantidad de piezas musicales.

\subsection{Objetivos e hipótesis}

A partir de estas consideraciones y desde una perspectiva fenomenológica, el objetivo general de esta investigación es determinar las relaciones que se entablan en esta celebración-ritual entre corporalidad, movimiento y poder o empoderamiento en los grupos humanos que participan considerando especialmente las bandas de sikuris y, al mismo tiempo, describir las transformaciones que tienen lugar en la percepción del mundo a partir de la experiencia corporizada que propone el paradigma del embodiment.

Los objetivos específicos son los siguientes: (1) analizar los movimientos, la organización y la participación de las bandas de sikuris, individual y grupalmente, es decir de cada una de ellas y del conjunto que componen las mismas; (2) evaluar los movimientos individuales de los integrantes de dichas bandas y (3) describir la Peregrinación como ritual: grupos que participan, desplazamientos en el espacio, tiempos e intervalos.

Al mismo tiempo, se propone como hipótesis el hecho de que los movimientos rituales, en tanto performance, son la expresión de los individuos y los grupos humanos y al mismo tiempo denotan ciertos aspectos de la estructura social, constantes y a la vez variables, que hacen al papel de actores y grupos sociales.

\section{Marco teórico y conceptual}

Esta investigación adopta como marco teórico y conceptual el paradigma del embodiment (Csordas 1994), inserto en la fenomenología, entendido como «campo me- 
todológico indeterminado definido por experiencias perceptuales y por el modo de presencia y compromiso con el mundo» (Csordas 2011: 83), mientras que el cuerpo es una entidad biológica y material. El «cuerpo vivido» es el punto de vista metodológico y no un objeto de estudio. Esto significa que la experiencia corporizada es el punto de partida para analizar la participación del hombre en el mundo (Csordas 1994, 2004, 2011) y, al mismo tiempo, constituye la base sobre la cual se apoya este estudio. Es importante aclarar que en este trabajo se concibe el embodiment tanto desde el punto de vista de quien investiga como del de los actores.

Siguiendo a Merleau-Ponty (1993), la fenomenología es el estudio de las esencias. Este autor re-sitúa las esencias dentro la existencia y sólo se comprende al mundo por su factibilidad; propone volver a la experiencia real y primordial en la cual el objeto está presente y vivo, como punto de partida para analizar una sociedad. Hay dos conceptos clave en Merleau-Ponty (1993) que interesan en este trabajo: la percepción en tanto comunión con el mundo y la «carne». El primero implica que el sujeto conoce un cierto medio de existencia o se sincroniza con él. El segundo supone una unidad entre sujeto y cosa que implica una experiencia pre-objetiva. El cuerpo y el mundo se comunican entre sí por la factibilidad de la «carne» sintiente y sensible que no se desliga del mundo. Su obra descubre de este modo la dimensión pre-objetiva del ser, que es ser-en-el-mundo.

Csordas (2011) propone reconsiderar la obra de Merleau-Ponty (1993) y Bourdieu (1991a), poniendo en primer plano los conceptos de percepción y práctica. Para Merleau-Ponty, la percepción imbricada con el mundo cultural, comienza en el cuerpo y llega a los objetos a través del pensamiento reflexivo; no hay distinción sujeto-objeto ya que somos en el mundo. El análisis comienza con el acto pre-objetivo de percepción y no con los objetos constituidos. Luego introduce a Bourdieu con su énfasis en el cuerpo socialmente formado como sustrato de la vida colectiva y resuelto en el dominio empírico de la práctica, paralelo y compatible con el análisis de Merleau-Ponty centrado en el dominio de la percepción. La unión del habitus con la noción de preobjetivo hace posible un embodiment que no necesita restringirse al micro-análisis personal, sino que es posible extenderlo a lo comunitario (Csordas 2011).

Otro pensador que juega un papel esencial en esta revalorización del cuerpo es Nietzsche (1972) quien redefine al sujeto, siendo el cuerpo la energía más grande y elige la voluntad de poder con la que intenta transformar al mundo (Citro 2009a, 2009b, 2011). Por otra parte, Foucault (1987) propone descubrir el cuerpo como un objeto, blanco de poder, y entonces las disciplinas son formas de poder, al tiempo que plantea la regulación del espacio y del tiempo en las sociedades.

También interesa aquí el planteamiento de Marcel Mauss (1936) quien sostiene que el modo en el cual los seres humanos aprenden a usar el cuerpo en cada sociedad -técnicas del cuerpo- es un medio importante de socialización y estas técnicas pueden ser modeladas por la sociedad mediante la educación organizada y programada o bien surgir por imitación espontánea. Al mismo tiempo, desarrolla las nociones de persona, individuo, personaje -como papel que el individuo juega en los dramas sagrados-, y grupo social (clanes) en distintas sociedades. Posteriormente, Alan Lomax demuestra su interés por vincular la danza con los movimientos de la vida cotidiana (Lomax 1962; Citro 2012). Para Lomax la danza es una representación de los patro- 
nes culturales y solo secundariamente expresa emociones individuales. Su función social es entonces la de reforzar modalidades de organización interpersonal y grupal (Lomax et al. 1968, citado en Citro 2012).

\subsection{Análisis del movimiento}

Laban $(1960,1987)$ describe al movimiento como la proyección visible de un sentimiento interior y la danza el medio de revelar las cualidades características de su ejecutante. Es además pensamiento, emoción, acción, expresión y está presente en todo aquello que forma el mundo externo e interno del hombre. Si bien el movimiento es territorio de la danza, Laban toma como objeto de estudio al primero. La teoria de Laban -Laban Movement Analysis- recogida en su globalidad por sus discípulos es una poderosa herramienta para analizar y comprender el movimiento en interacción constante con el entorno (Ros 2009).

Desde la perspectiva de este autor, el arte del movimiento es prácticamente una disciplina autónoma que habla por sí misma y, en la mayoría de los casos, en su propio idioma. Hay una relación casi matemática entre las motivaciones internas y las funciones del cuerpo, es decir entre impulso y función. Laban es el creador del método de observación y análisis del movimiento llamado Esfuerzo-Forma, que busca describir la potencialidad del movimiento humano como mediadora entre el mundo interno y externo. Propone además un interesante paralelo entre el movimiento en la vida individual y el movimiento del desarrollo de la humanidad y concluye que en ambos casos los estilos más primitivos se repiten (Laban 1960, 1987).

Además, las personas utilizan sus cuerpos y el espacio que las rodea. Los componentes del movimiento son para Laban: el cuerpo en sí mismo, es decir la estructura y la morfología corporal; el espacio en dónde el cuerpo se mueve considerando los patrones y tensiones espaciales de los movimientos del cuerpo y las formas que resultan y, finalmente, el esfuerzo. Cuerpo, espacio y esfuerzo son las tres categorías principales del cuerpo en movimiento, que se vinculan entre sí en ritmo y fraseo (Bartenieff y Lewis 1980).

Los componentes del esfuerzo, es decir del movimiento, son: flujo, espacio, peso y tiempo. Los tres últimos se vinculan con la atención, la intención y la decisión respectivamente. Es importante aquí el concepto de kinesfera. El cuerpo humano es tridimensional, es decir presenta tres ejes: longitud, ancho y profundidad. La unión de estos tres ejes da como resultado la propia kinesfera, es decir el espacio propio o privado, el espacio adherido (Bartenieff y Lewis 1980).

Por otra parte, Dalcroze (Bachmann1998) propone un método, denominado euritmia, que utiliza el espacio relacionando los movimientos y desplazamientos corporales, descubriendo de este modo las relaciones entre energía, espacio y tiempo. Para este autor la música es el estímulo para el movimiento y la danza, buscando la armonía del movimiento, mientras que para Laban la música se origina desde el movimiento rítmico del cuerpo y la improvisación; en ausencia de música se desarrolla la expresión motriz, siendo fundamental el impulso del movimiento en coordinación con la voluntad (Megías 2009; Lombardo 2012). 


\section{Metodología}

El trabajo de campo consistió en el relevamiento de la población en estudio y la observación libre y participativa de la celebración de la Virgen de Copacabana. También se llevaron a cabo algunas entrevistas libres realizadas a pobladores del área de estudio acerca de su modo de participación en este ritual. La documentación se realizó mediante libretas de campo y fotografías. La información etnográfica obtenida se ordenó mediante transcripciones, y fue analizada para confrontar y corroborar los datos obtenidos con las fuentes bibliográficas y etnohistóricas existentes.

Se utilizaron dos estrategias para lograr una observación objetiva y a la vez tratar de encarnar la experiencia. Por un lado, se participó en la bendición de las bandas de sikuris en la iglesia de Tilcara y se acompañó a la última de ellas hasta el pie de la montaña. Por otro, el día que la peregrinación desciende desde el abra hacia el pueblo, se realizó el camino inverso ascendiendo desde las primeras horas de la mañana para alcanzar a las bandas y a la Virgen en el tercer calvario o lugar de descanso. El recorrido fue de circa $4 \mathrm{~km}$ de ida en ascenso y $4 \mathrm{~km}$ de vuelta, hacia abajo. Desde un punto elevado de la montaña se observaron las bandas y los grupos de promesantes durante cerca de dos horas, se tomaron fotografías y se filmaron varias secuencias y recorridos. Por último, se acompañó a la Virgen hasta su entrada a Tilcara.

El análisis de los movimientos involucrados en la peregrinación y en las bandas de sikuris se llevó a cabo siguiendo los lineamientos de Laban considerando al mismo tiempo el planteo de Dalcroze (Bachmann1998) referido a las relaciones entre energía, espacio y tiempo. Se plantean a continuación los pasos a seguir con el fin de lograr una descripción lo más acertada posible (adaptado de Laban 1987).

Modo de usar el cuerpo: ejes (vertical, horizontal y sagital), parte superior e inferior del cuerpo, lateralidad, diagonales, dirección de los movimientos (adelante-atrás, arriba-abajo); apoyo en el suelo, movimientos simétricos o asimétricos, movimientos simultáneos o sucesivos. Espacio: división y niveles de espacio, gestos, cambios de frente, forma de los giros y pasos. Peso: cambios, tensión, distribución de los acentos, fraseo, uso de distintas partes del cuerpo. Tiempo: pasos rápidos o lentos, repetición de un ritmo. Movimiento descrito en función de las acciones espaciales: ritmo y acento; la forma que toma el cuerpo para realizar un movimiento.

Se consideran también los siguientes aspectos para realizar el análisis de la secuencia de movimientos: significado o sentido de los movimientos dirigidos a distintas direcciones del espacio, características que correspondan a movimientos altos, medianos o profundos, giros abiertos y cerrados, movimientos simétricos y asimétricos, naturaleza de los patrones trazados por los pasos en el suelo y formas en el aire: gestos de brazos y piernas.

\section{La peregrinación y el ritual}

La celebración de la Virgen de Copacabana en el Abra de Punta Corral que se analiza tuvo lugar los días 24 al 27 de marzo de 2013. No obstante, esta celebración no se reduce a cuatro días, sino que abarca un proceso de preparación, anterior y posterior 

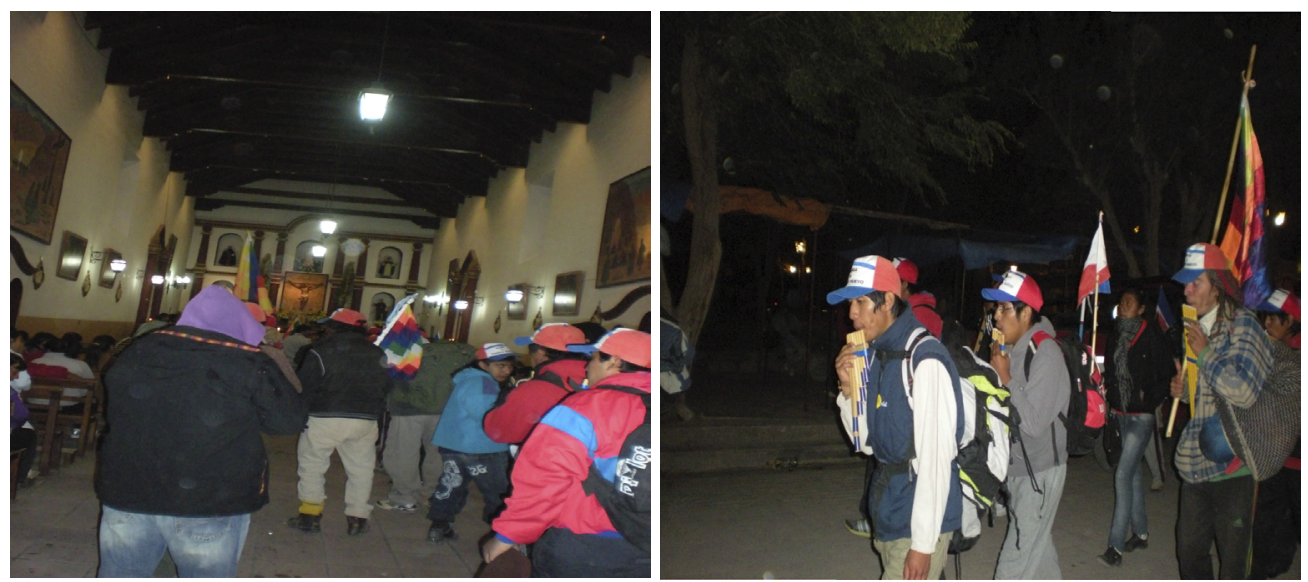

Figura 1: Bandas de sikuris en Tilcara: A) en la iglesia luego de haber recibido la bendición; B) por las calles hacia el Abra de Punta Corral.

a la peregrinación, que también es parte del ritual e implica responsabilidades y posicionamientos sociales de fuerte reconocimiento en la comunidad. En primer lugar, se describen los distintos acontecimientos y luego los movimientos individuales y grupales, de acuerdo con la perspectiva y el marco teórico adoptados.

El domingo 24 de marzo, durante la Misa de Ramos realizada en la iglesia de Tilcara, comenzó la bendición de las bandas de sikuris, la cual finalizó el lunes 25 a media noche. Las 75 bandas que participaron en esta oportunidad fueron a la iglesia para recibir la bendición. Cada una de ellas ingresó de rodillas por la nave central y se detuvo a pocos pasos del altar para que el sacerdote la bendijera; mientras, sus integrantes permanecieron arrodillados con sus respectivos instrumentos. Terminada la bendición se pusieron de pie y ejecutaron la música preparada especialmente para esta ocasión. Mientras iban tocando, retrocedían, de modo que nunca le daban la espalda al altar (Figura 1 A). Ya en la puerta de la iglesia, lanzaron bombas de estruendo e iniciaron la caminata; recorrieron primero el atrio, rodearon la plaza e ingresaron a las calles para dirigirse a las montañas al son de un ritmo de marcha (Figura $1 \mathrm{~B}$ ).

Se acompañó a la última banda que salió de la Iglesia luego de ser bendecida para experimentar de algún modo la partida y los primeros pasos hacia el Abra de Punta Corral. Por las calles de Tilcara la banda avanza al ritmo de su música ejecutando tambores, platillos y sikus, con paso definido y rápido. Se comunican entre ellos, cosa que será menos frecuente al comenzar el ascenso (Figura $1 \mathrm{~B}$ ).

La experiencia más definida e intensa tuvo lugar al llegar al pie de la montaña y observar a la banda alejarse e ir hacia arriba. En ese punto del espacio dieron un pequeño y rápido giro; luego avanzaron con total naturalidad y decisión y comenzaron a subir, tocando sus instrumentos aún, aunque casi todo el ascenso lo hacen en silencio por la escasez de oxígeno en la altura (van coqueando para compensarlo); se dirigían hacia un lugar absolutamente familiar y conocido lo cual se reflejaba en la marcha. Esta naturalidad es llamativa e impactante ya que, a pesar de no ser un acontecimiento que tiene lugar todos los días, se percibe como cotidiano y al mismo tiempo como 

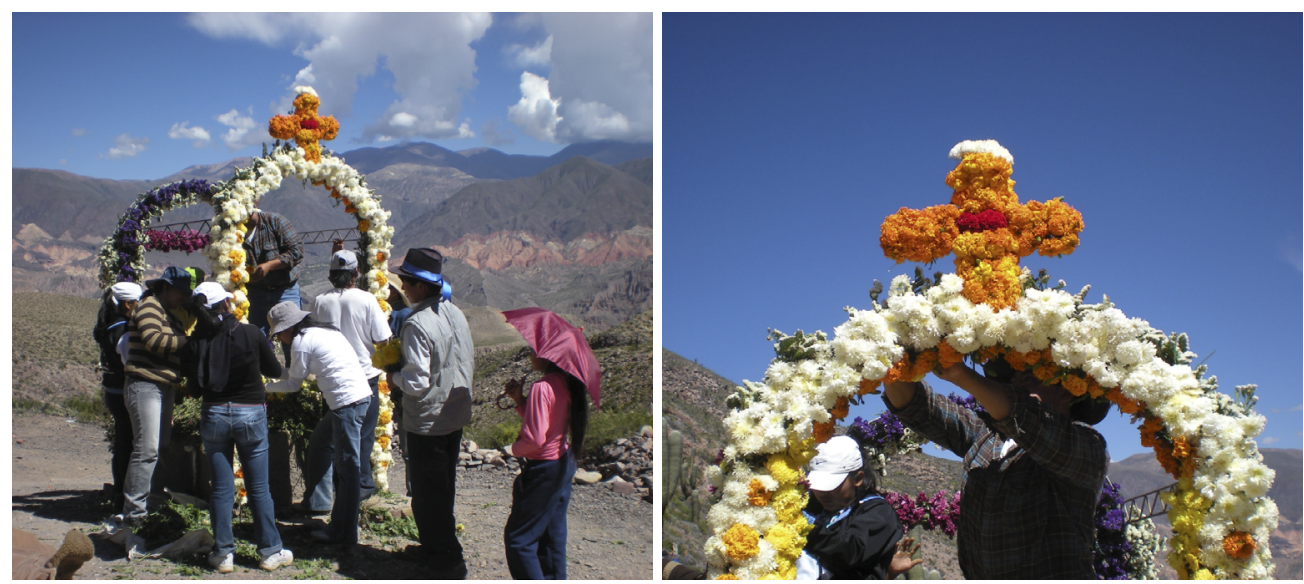

Figura 2: Construcción comunitaria de las ermitas.

conducta plenamente incorporada a la vida de los actores que llevan a cabo el ritual. Se trata de algo que no piensan ni tienen que decidir, simplemente lo realizan: ascienden hasta el Abra de Punta Corral cada año; caminan muy cargados, no sólo por los instrumentos que incluyen enormes tambores, sino también con la carga para toda una jornada y la noche. Las bandas están integradas actualmente por muchos niños de 10-12 años más o menos. Los más pequeños son llevados por sus padres desde que nacen y seguramente irán al Abra por sí mismos toda la vida.

El día martes 26 de marzo a la mañana temprano llegaron casi todos los promesantes y las bandas a la cima de la montaña, situada a unos $3800 \mathrm{msnm}$. Algunas personas que no integran las bandas suben y bajan solas ya que el ascenso no es algo muy compartido, más bien cada uno debe organizarse para hacerlo. En el camino hay calvarios, es decir lugares de descanso; en casi todos ellos se arman hermosas ermitas con flores blancas y amarillas (Figura 2).

El día miércoles 28 a las 5:30 horas, después de una misa, partió la imagen de la Virgen de Copacabana desde el Abra de Punta Corral, acompañada por la de la Virgen de la Candelaria, para recorrer un trayecto que tuvo una sola parada a mitad del camino, en el calvario de Chilcaguada. Las bandas de sikuris fueron adelante de ambas imágenes, que distintas personas se iban turnando para llevar. El trayecto total es de $26 \mathrm{~km}, 13 \mathrm{~km}$ de ida y $13 \mathrm{~km}$ de vuelta, desde la base de la montaña.

Ese mismo día 28 de marzo, al ascender a la montaña $(c a$. de $4 \mathrm{~km})$, como se explicó anteriormente (véase Metodología), fue posible observar a las bandas (Figuras 3, 4 y 5 B) y demás promesantes descendiendo desde el Abra hacia el pueblo llevando ambas vírgenes (Figura 6). Muchos empiezan el descenso por la mañana temprano ya que como dijeron algunos de los entrevistados:

«.... después no se puede avanzar... cuando bajan las bandas y la Virgen... nosotros hicimos una promesa y ya está... estuvimos con la Virgen arriba y en la misa hoy, nos dio su bendición... estamos muy contentos y cansados pero vale la pena... ya estuvimos el año pasado» (Juan y Paula Gómez, matrimonio procedente de Salta) 

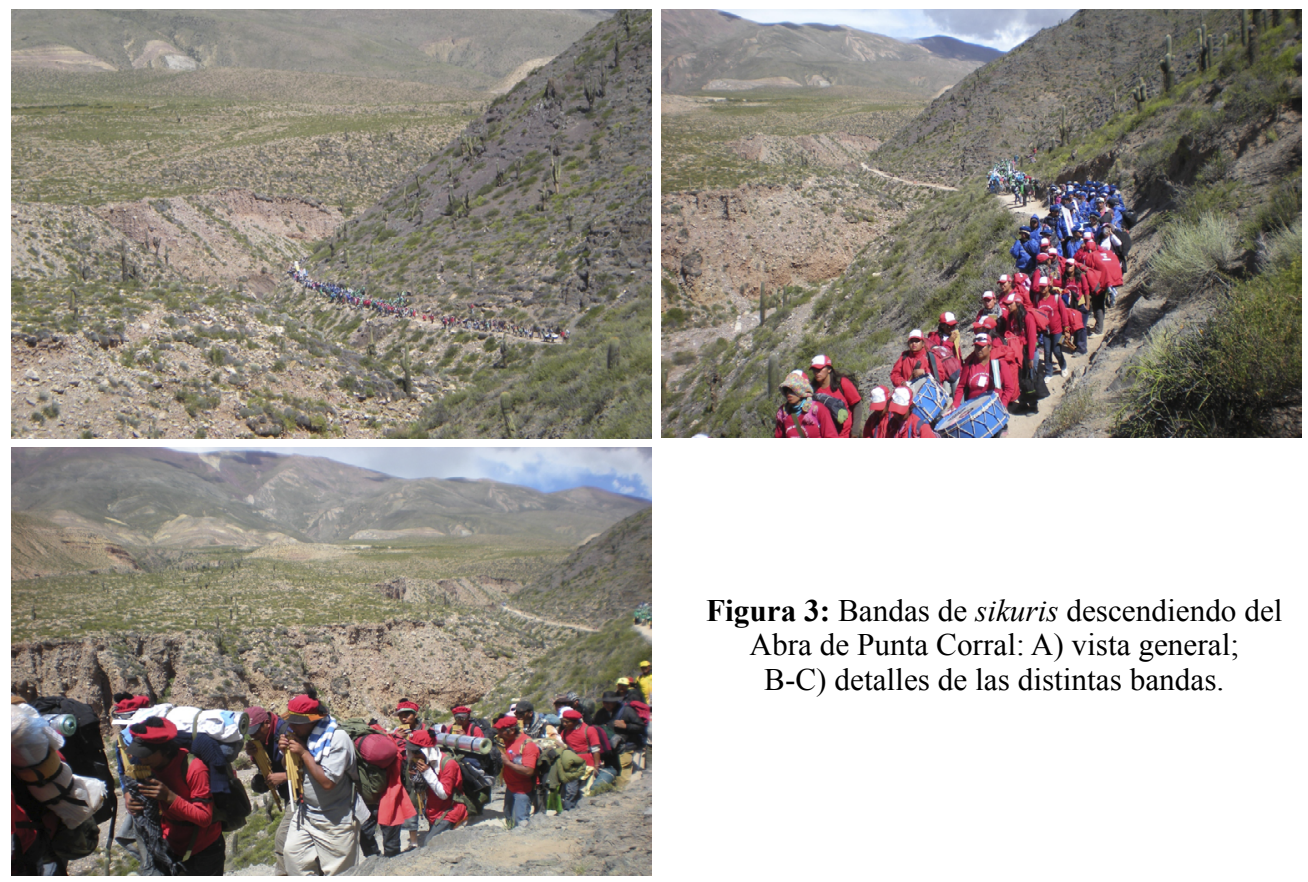

Figura 3: Bandas de sikuris descendiendo del Abra de Punta Corral: A) vista general; B-C) detalles de las distintas bandas.

«... si uno no baja ahora, hasta la noche no llega al pueblo... por eso me apuro, hay que adelantarse a las bandas y a la Virgen... lo digo porque hace 18 años que vengo y sé cómo es esto» (Manuel Ramos, poblador de Tilcara).

Se destaca también la construcción de ermitas con ramas y flores por los pobladores locales que puede observarse en el camino. La Virgen irá entrando en algunas de ellas a su paso (ver Figura 2).

La observación de las bandas, que se prolongó durante más de dos horas, permitió reconocer el universo de las mismas. Cada una de ellas -integrada por 30 a 35 personas aproximadamente, hombres, mujeres y niños- tiene un color que predomina claramente, un sonido, una vestimenta, un modo de expresarse y un ritmo; una a una fueron apareciendo en la montaña. Miles de personas venían desde el Abra con mucha carga, tocando sus instrumentos con algunos intervalos, coqueando casi todos, satisfechos por el logro y el deber cumplido (Figuras 3 y 4). Es importante mencionar las diferencias que se evidencian en la actitud de los integrantes de las bandas antes del ascenso (por las calles de Tilcara) y en el descenso, durante el cual se desplazan con mayor soltura y más alegres (Figura 5).

A las 16 horas, la Virgen de Copacabana acompañada por la Virgen de la Candelaria, pasó por el punto de observación elegido, avanzando por detrás de las bandas. Esto también reflejaba la naturalidad de un acontecimiento que simplemente ocurre. La Virgen descendía desde su lugar en el Abra de Punta Corral: hecho simple y extraordinario al mismo tiempo.

El siguiente paso consistió en seguir a la procesión que acompañaba a la Virgen. La marcha era muy lenta y el camino muy escarpado; los hombres formaban una fila 

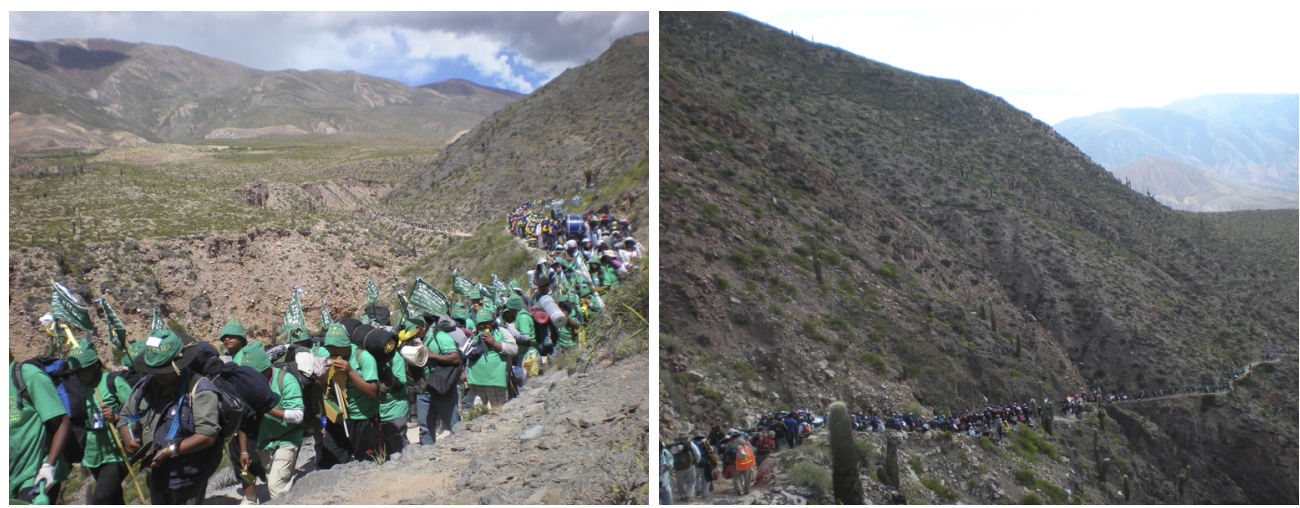

Figura 4: Bandas de sikuris descendiendo del Abra de Punta Corral: A) detalle de una banda; B) vista general del descenso luego del último calvario.
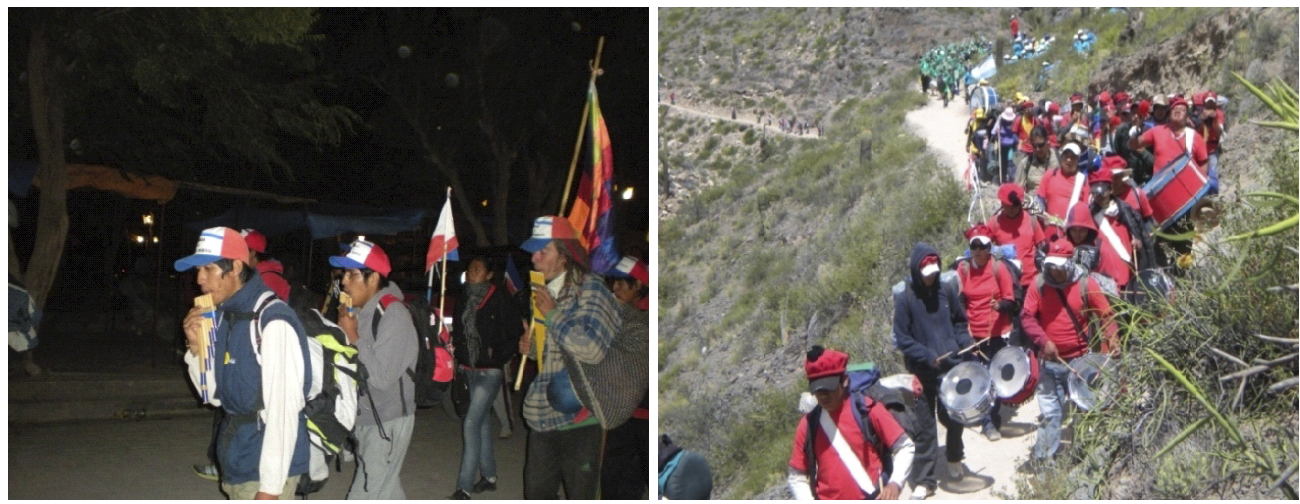

Figura 5: Actitudes, posturas y gestos de los integrantes de las bandas:

A) antes del ascenso; B) durante el descenso.
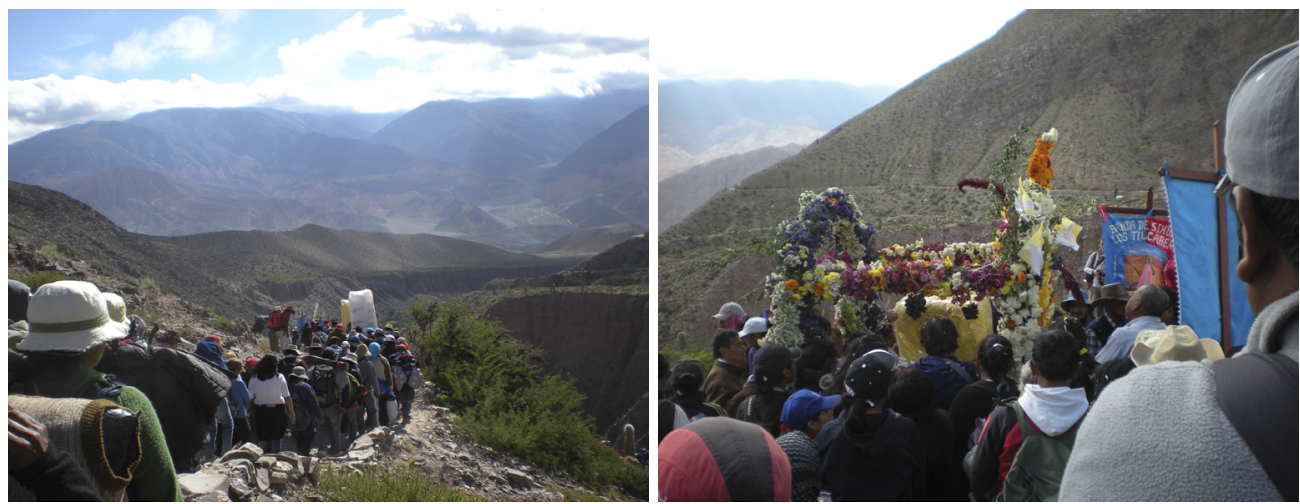

Figura 6: Descenso de la Virgen desde el Abra de Punta Corral: A) promesantes llevando a la Virgen de Copacabana acompañada por la Virgen de la Candelaria; B) entrada de la Virgen de Copacabana en una ermita ubicada en el último calvario. 
y se turnaban para llevarla (Figura 6 A). Al llegar a uno de los últimos calvarios, las personas que estaban esperando, acompañaron a la Virgen de Copacabana hasta su entrada en una de las ermitas que fabrican con toda dedicación; entonces la aplaudieron y la bañaron de flores (Figura $6 \mathrm{~B}$ ). Luego siguió su recorrido hacia la base -Barrio Usina- en donde había también arcos construidos como las ermitas, con ramas y flores. Fueron llegando las bandas y luego la Virgen a las 18:30 horas con aplausos, pañuelos blancos y mucha emoción. En el punto de encuentro se celebra una misa. Luego siguen camino hasta llegar a la iglesia de Tilcara en donde la celebración comenzó, y ahora concluye adquiriendo su cierre. La Virgen es recibida y bienvenida, y allí permanecerá durante todo el año.

\section{Movimientos grupales, individuales y personales}

Siguiendo los lineamientos de Laban (1987) y considerando al mismo tiempo el planteamiento de Dalcroze (1998), se pasa a analizar los distintos movimientos. La primera descripción de movimientos grupales corresponde a la bendición de la última banda y su recorrido hasta el pie de la montaña. Los integrantes de la misma entran a la Iglesia por la nave central arrodillados para recibir la bendición. Luego se ponen de pie, ejecutan su música y se retiran caminando hacia atrás (ver Figura 1A). Hay movimientos en dos planos: sagital, hacia adelante y hacia atrás, y vertical hacia abajo y arriba, al arrodillarse y ponerse de pie. Es interesante destacar que el movimiento sagital hacia atrás adquiere la misma definición que hacia adelante y no implica un cambio de frente ya que lo realizan con el foco y la intención dirigida hacia el altar que sigue siendo su objetivo hasta que salen de la iglesia. Entonces, si bien este movimiento hacia atrás es definido, adquiere más liviandad ya que seguramente lo llevan a cabo con una intención que se reparte focalizándose hacia atrás porque deben salir de la iglesia y hacia adelante, punto inicial de destino que continúa siendo objetivo. Al llegar a la puerta cambian de frente con un pequeño giro cerrado y rápido, desplazándose nuevamente hacia adelante en el plano sagital.

Es importante advertir el sentido o la finalidad de los movimientos dirigidos a distintas direcciones del espacio en la secuencia descrita en el párrafo anterior. En primer término, van hacia adelante para recibir la bendición que los habilita para el ascenso y luego hacia atrás para salir a las calles. No obstante, no hay giro para entrar e inaugurar el segundo momento, persiste la primera intención representada de algún modo en el altar y comienza a nacer la segunda, que tiene como meta alcanzar el Abra. Entonces, las direcciones y los planos que entran en juego denotan de algún modo las intenciones y los objetivos de los miembros de las bandas.

Durante el trayecto que comienza al salir de la Iglesia los movimientos son libres y naturales pero muy definidos: van hacia adelante. Prevalece el plano sagital porque ante todo avanzan, y luego el plano horizontal ya que comparten entre ellos y se comunican entre sí mientras caminan por las calles hacia la montaña con pasos rápidos y a un ritmo constante (ver Figura 1B). Al llegar a la base, hacen un giro más bien rápido y abierto hacia la izquierda y en ese momento comienzan el ascenso, como se dijo más arriba. Sigue prevaleciendo el plano sagital hacia adelante, para alcanzar en una segunda instancia el plano vertical al ir hacia la cima. Van hacia adelante y hacia 
arriba, no obstante se advierte, y es muy definido, el predominio del plano sagital. El plano horizontal no es marcado en el ascenso, ya que no hay un movimiento muy definido que se dirija hacia los otros participantes o miembros del grupo. Existe sin duda la posibilidad de compartir con solidaridad, pero su expresión no es muy notoria ni prevalece. Por lo tanto, el movimiento de las bandas es sagital y vertical, y, en tercer término, horizontal.

Las siguientes observaciones se relacionan con los movimientos que realizan las bandas durante el descenso. En este momento sigue predominando el movimiento sagital, ya que avanzan para regresar a la base. No obstante, si bien prevalece esta dirección, no es tan definida como al iniciar el ascenso. Esto puede deberse a la fuerte intención de llegar al Abra que existía al comienzo; ahora regresan y el objetivo principal de llegar a la cima de la montaña ya está alcanzado y sólo necesitan concluir el ritual. Pero también es cierto que en el descenso comienza a marcarse más el plano horizontal, al ponerse en juego la comunicación entre los integrantes de cada banda, cosa que no ocurría en el ascenso. Durante el regreso los movimientos son más sueltos y espontáneos. Al ampliarse la horizontalidad no es tan marcado el plano sagital, aunque no se pierde en ningún momento. Entonces, predomina el plano sagital, seguido por el horizontal y luego el vertical dado por el movimiento de descenso (Figuras 3, 4 y 5B).

Considerando ahora el movimiento de cada banda, adelante va un integrante de la misma -dirigente- con el redoble y avanza haciendo movimientos hacia adelante y a los costados, y algunos giros. Levanta el bastón por el aire y se mueve marcando el pulso y el ritmo de la banda, tanto en el paso como en la música que ejecuta. Por detrás vienen los tambores (2-6); luego los platillos (1-3); los bombos (1-2) y por último los sikus, que constituyen el mayor número (20 como mínimo). Los instrumentos son tocados por hombres, mujeres y muchas veces por niños (Figuras 3B-C, 4A y 5B).

Es interesante aquí describir el movimiento en función de las acciones espaciales -ritmo y acento-, ya que es claro aquél que realizan todos los miembros al son del instrumento que ejecutan. Sus cuerpos toman la forma que la música les otorga y caminan siguiendo el propio pulso y el de la banda, y el ritmo de la música que ejecutan. Se advierte que los movimientos de quienes tocan los sikus -cañeros- son más rápidos y livianos; se inclinan hacia adelante, hacia los costados y abajo, formando arcos con sus cuerpos en el espacio, siguiendo muy claramente la trayectoria del sonido que surge de sus instrumentos (Figuras 3C y 4A). En cambio, los ejecutantes de los tambores, en especial de los más grandes, se mueven con más costo y sus movimientos, limitados por el peso de los instrumentos que llevan, son cerrados y poco amplios (Figuras 3B y 5B). Por otra parte, quienes tocan platillos y campanas se mueven con más soltura, aunque con menos gestos y variedad de movimientos expresivos que los que ejecutan los sikus.

Por otra parte, existen algunas diferencias en los movimientos de los promesantes que van atrás de la Virgen. En este caso la marcha es muy lenta ya que hay un monto de energía importante que emplean para llevarla. El movimiento en el plano sagital es definido, no obstante se van pasando unos a otros al turnarse para realizar esta tarea. Hay movimientos horizontales definidos al comunicarse entre ellos de algún modo estos turnos; también movimientos verticales de descenso. Caminan extremadamente cerca unos de otros, parecen ser uno en la tarea de llevar a la Virgen; los pasos son muy cortos y cautelosos (Figura 6). 
Con respecto a la kinesfera, durante el ascenso y más aún en el descenso de las bandas, es pequeña para cada integrante, ya que se desplazan muy cerca unos de otros; sin embargo parecen estar solos, aún en esa proximidad. Las kinesferas se tocan todo el tiempo, pero no se invaden ya que cada uno conserva la propia, es decir su espacio personal. A diferencia de lo que ocurre en las bandas, las kinesferas de los promesantes que llevan y acompañan a la Virgen se aproximan y parecen solaparse muchas veces, diluyéndose unas en otras. La kinesfera, entendida como el espacio propio de cada persona, se amplía y diversifica existiendo un espacio propio o personal que se vincula con aquél compartido con quienes caminan al lado. También hay un espacio de la banda, a su vez relacionado con el espacio social que abarca a todas las bandas; por encima, el espacio ritual que integra a quienes comparten la celebración.

Resumiendo lo dicho hasta aquí, prevalecen los movimientos en el plano sagital tanto en el ascenso como en el descenso; luego, el movimiento vertical, ya que suben y bajan y el movimiento horizontal al dirigirse hacia los otros con quienes comparten el camino, mucho más marcado en el descenso. El movimiento vertical hacia arriba y abajo es claro espacialmente, es decir suben y bajan, pero también existe un movimiento de ascenso figurado en el plano de las creencias, tal vez espiritual y sin duda personal, que al menos durante esa jornada no tiene retorno y en esto radica el sentido más profundo del ritual que se desarrolla en el ascenso y el descenso a la montaña. Desde una perspectiva global, se observa un movimiento que puede describirse como circular -ida y vuelta- que va desde el pueblo al Abra y nuevamente al pueblo. La Virgen también completa este ciclo ya que asciende 15 días antes a la cima y luego baja siguiendo la misma trayectoria. Regresará al santuario en el Abra de Punta Corral los próximos años. Además, el uso del espacio y el vínculo entre movimientos y desplazamientos corporales tal como plantea Dalcroze (Bachmann1998) ponen en evidencia las relaciones: energía, espacio y tiempo en todos los casos analizados.

\section{Discusión y conclusiones}

A través de este estudio, y siguiendo el objetivo general planteado, fue posible descubrir las relaciones que se entablan en esta celebración-ritual entre corporalidad, movimiento y poder o empoderamiento. El movimiento confiere poder a los individuos y por lo tanto a los grupos humanos, siguiendo el pensamiento de Nietzsche (1972), y este empoderamiento les facilita el logro de las metas que se proponen. Es interesante destacar que esto se evidencia en las claras diferencias que se observan en la actitud de los integrantes de las bandas antes del ascenso (por las calles de Tilcara, Figura $5 \mathrm{~A}$ ) y durante el descenso (Figura 5B), cuando dicho empoderamiento tuvo lugar mediante el movimiento, la música y las metas alcanzadas a través de los mismos. Estos individuos son seres-en-el-mundo y están-en-el-mundo, «haciéndose carne» con el paisaje y el ritual, a través de los movimientos y la movilidad que el último implica. Las relaciones de poder son evidentes en hechos tales como la decisión acerca de las bandas de sikuris que tocarán en cada momento acompañando a la Virgen en su descenso, el cual tiene lugar en el Abra la tarde anterior al mismo. Y estas acciones están claramente vinculadas con el movimiento de descenso en sí mismo, el movimiento de 
cada banda y la movilidad en general de los grupos y bandas. Se entrelazan entonces la corporalidad, los movimientos y el poder en este ritual.

De acuerdo con lo observado y analizado, los movimientos en tanto performance son la expresión genuina de cada individuo y de los grupos humanos que hacen al papel de actores y grupos sociales y al mismo tiempo denotan ciertos aspectos de la estructura social, constantes y a la vez variables en tiempo y espacio. Y esto se evidencia sin lugar a duda a distintos niveles, comenzando por las bandas de sikuris que expresan lo propio a través de su música, sus colores, vestimentas y un modo particular de participar y de estar en la celebración, como modo de estar-en-el-mundo.

A un nivel más amplio, todos los que participan y de algún modo llevan a cabo este ritual y lo re-crean cada año, expresan su pertenencia, manifiestan costumbres, creencias, tradiciones, plasman deseos y pedidos. En síntesis, el rito resume tanto el pasado - recreado- a través de aquellas acciones que año a año se repiten y tienen su origen tiempo atrás, como el presente en el cual ocurre la peregrinación-ritual que actualiza el pasado y se proyecta hacia el futuro, ya que existe una idea implícita de continuidad en el tiempo que permite predecir que todo comenzará otra vez en los años sucesivos. La materialidad corporal de quienes participan, en especial de los integrantes de las bandas, se modifica y estos cambios se relacionan con la socialización de los performers, quienes a través de determinados modos somáticos de atención constituidos culturalmente (Csordas 1994), prestan atención al propio cuerpo y al cuerpo de los otros y sus movimientos para poder responder a los mismos. Esto comienza por lo general a temprana edad y continúa toda la vida, por lo tanto, otorga pertenencia a un pequeño grupo, la banda de sikuris, y a otro mucho más amplio: la sociedad en la cual el ritual se desarrolla. Sin duda, el ritual socializa a quienes lo llevan a cabo y el cuerpo en movimiento es el vehículo para lograrlo.

En relación con el último planteamiento, es interesante también retomar la propuesta de Mauss $(1936,1950)$ vinculada con las técnicas del cuerpo y el papel que éstas juegan en la socialización de los individuos. En este sentido, la participación en las bandas de sikuris es uno de los modos más importantes de inclusión social en el NOA. Esta participación implica una determinada corporalidad y un particular uso del cuerpo, propios de cada banda y, al mismo tiempo, de todos los integrantes de las bandas (Figuras 3, 4 y 5). También es posible hacer referencia a Lomax (1962) para quien la función social de la danza -en este caso movimientos rituales- consiste en reforzar modalidades de organización interpersonal y grupal, tal como se dijo más arriba. Al mismo tiempo, son relevantes las nociones de persona, individuo, personaje y grupo social que Mauss $(1936,1950)$ propone, ya que se analizó el lugar que cada individuo como persona ocupa en la celebración del ritual y al mismo tiempo el grupo, es decir las bandas con sus distintos personajes en tanto rol que el individuo juega en los dramas sagrados.

Asimismo, retomando a los otros autores citados en el marco teórico, es importante señalar en qué medida sus abordajes fueron útiles para llevar a cabo este trabajo. En este sentido, el concepto de habitus vinculado con la práctica que propone Bourdieu (1991b), conduce al sistema de disposiciones adquiridas que en este caso se reflejan en las conductas de los integrantes de las bandas y de todos los que participan en la peregrinación. Son importantes aquí las prácticas, así como también las conductas y disposiciones que surgen de las mismas. 
Es interesante también hacer referencia a la idea que plantea Foucault (1987) acerca de la regulación del espacio y del tiempo en las sociedades. En relación con esto, la peregrinación refleja el espacio que la sociedad ritualiza cada año en determinado momento, marcando las pautas y, de algún modo, los límites de la celebración. Asimismo, cada banda funciona como un pequeño universo social con conductas preestablecidas y acordadas que les permiten desempeñarse de un determinado modo.

Siguiendo la propuesta de Csordas (2011), el eje en torno al cual se realizó este estudio está conformado por los conceptos de percepción sensu Merleau-Ponty (1993) y práctica sensu Bourdieu (1991a). El análisis comenzó con el acto pre-objetivo de percepción en el cual sujeto y objeto constituyeron el locus de la existencia, permitiendo al primero encontrar una nueva dimensión de su propio ser y estar-en-el-mundo. Asimismo, se puso énfasis en el cuerpo socialmente formado como sustrato de la vida colectiva y resuelto en la práctica. La unión del habitus con la noción de pre-objetivo hizo posible trascender el análisis meramente individual y abarcar lo social-comunitario.

Merleau-Ponty, Bourdieu y Foucault parten de tres loci diferentes -existencia, habitus y relaciones de poder-y llegan a diferentes concepciones en relación con el vínculo cuerpo-mundo: estar en el mundo, reciprocidad cuerpo-mundo y cuerpo por encima del mundo respectivamente (Csordas, comunicación grupal en clase). Al respecto, se analizaron las bandas y demás participantes por su modo de estar en la peregrinación, en tanto estar-en-el-mundo, en donde cada individuo y el grupo en sí mismo transforman al entorno y al mismo tiempo son transformados por aquello que dichas prácticas producen y generan en el mundo. También el cuerpo está en cierta forma por encima del mundo, considerando la regulación del espacio y del tiempo que tiene lugar mediante rituales, como el que aquí se analizó.

En síntesis, a partir de esta investigación se intentó delinear el análisis fenomenológico de un modo de expresión en determinado grupo humano que se manifiesta a través del movimiento, la corporalidad y las relaciones de poder en el NOA, como parte del mundo andino. Se trató de experimentar y aprehender una pequeña parte de la realidad para luego explicarla y al mismo tiempo comprender la cotidianeidad de hechos extraordinarios, tales como los rituales.

Agradecimientos: A Thomas Csordas y Silvia Citro por el excelente seminario acerca del Embodiment que dictaron en la Universidad de Buenos Aires en julio de 2012, el cual me aportó una nueva perspectiva que sin duda cambió mi modo de comprender todo aquello que deseo describir y analizar. A Carlos Zanolli por sus sugerencias y por facilitarme su trabajo, valioso antecedente en relación con el tema de esta investigación.

\section{Referencias bibliográficas}

BACHMANN, Marie-Laurie

1998 La rítmica Jaques-Dalcroze: una educación por la música y para la música. Madrid: Pirámide

BARTENIEFF, Irmgard y Dori LEWIS

1980 Body Movement: Copying with the Environment. Nueva York: Gordon and Breach. 
Bourdieu, Pierre

1991a «Estructuras, habitus, prácticas», en El sentido práctico, pp. 91-111. Madrid: Taurus.

1991 b «La creencia y el cuerpo», en El sentido práctico, pp. 113-135. Madrid: Taurus.

Citro, Silvia

2009a «Ancianos: Los cuerpos del poder», en Cuerpos Significantes. Travesías de una etnografía dialéctica, Silvia Citro, coord., pp. 175-242. Buenos Aires: Biblos.

2009b «Variaciones sobre la corporalidad», en Cuerpos Significantes. Travesías de una etnografía dialéctica, Silvia Citro, coord., pp. 43-82. Buenos Aires: Biblos.

2011 «La Antropología del Cuerpo y los cuerpos en-el-mundo. Indicios para una genealogía (in)disciplinar», en Cuerpos Plurales. Antropología de y desde los cuerpos, Silvia Citro, coord., pp. 17-58. Buenos Aires: Biblos.

2012 «Cuando escribimos y bailamos. Genealogías y propuestas teórico-metodológicas para una antropología de y desde las danzas», en Cuerpos en movimiento. Antropología de y desde las danzas, Silvia Citro y Patricia Aschieri, coords., pp. 17-64. Buenos Aires: Biblos.

CORTÁzAr, Augusto

1965 «La Virgen de Punta Corral». Selecciones Folkloricas 2: 29-44.

Costilla, Julia

2010 «El milagro en la construcción del culto a Nuestra Señora de Copacabana (Virreinato del Perú, 1582-1651)». Estudios Atacameños 39: 35-56.

CSORDAS, Thomas

1994 «The Body as Representation and Being-in-the-World», en Embodiment and Experience, Thomas Csordas, ed., pp. 1-24. Cambridge: Cambridge University Press.

2004 «Asymptote of the Ineffable». Current Anthropology 45 (2): 163-85.

2011 «Modos somáticos de atención», en Cuerpos plurales. Antropología de y desde los cuerpos, Silvia Citro, coord., pp. 83-104. Buenos Aires: Biblos.

FOUCAULT, Michel

1987 «Los cuerpos dóciles», en Vigilar y castigar, pp. 139-174. Buenos Aires: Siglo XXI.

GISBERT, Teresa

1994 Iconografía y mitos indígenas en el arte, $2^{\mathrm{a}}$ edición. La Paz: Gisbert y Cía.

LABAN, Rudolf

1960 The Mastery of Movement, $2^{\mathrm{a}}$ edición. Londres: Macdonald \& Evans.

1987 El dominio del movimiento. Caracas-Madrid: Editorial Fundamentos.

LAFÓN, Ciro R.

1967 «Fiesta y religión en Punta Corral (Provincia de Jujuy)». Runa. Archivo para las ciencias del Hombre 10 (1): 256-289.

Lomax, Alan

1962 «Song, Structure and Social Structure». Ethnology 1 (4): 425-451.

Lomax, Alan, Conrad Arensberg, Edwin E. Erickson, Victor Grauer, Norman Berkowitz, Irmgard Bartenieff, Forrestine Paulay, Joan Halifax, Barbara Ayres, Norman N. Markel, Roswell Rudd, Monika Vizedom, Fred Peng, Roger Wescott y David Brown.

1968 Folk Song Style and Culture. Washington D.C.: American Association for the Advancement of Science. 
LOMBARDO, D. Ricardo

2012 Análisis y aplicación de la teoría de Laban y del movimiento creativo en la dirección de conjuntos instrumentales en la formación del maestro en educación musical. Tesis doctoral. Valladolid: Universidad de Valladolid.

LuJÁN LÓPEZ, Francisco B.

2002 «Nuestra Señora de Copacabana, una devoción andina patrona de Rubielos Altos (Cuenca). Su origen y difusión». Revista Murciana de Antropología 8: 193-246.

MachaCA, Antonio R.

2004 Los sikuris y la Virgen de Copacabana del Abra de Punta Corral. Tilcara: Municipalidad de San Francisco de Tilcara, Jujuy.

MAuss, Marcel

1936 «Les techniques du corps». Journal de Psychologie 32 (3-4).

1950 Sociologie et anthropologie. Paris: Presses Universitaires de France.

Megías, María Isabel

2009 Optimización en procesos cognitivos y su repercusión en el aprendizaje de la dan$z a$. Tesis Doctoral. Valencia: Universidad de Valencia.

Merleau-Ponty, Maurice

1993 «La espacialidad del propio cuerpo y la motricidad», en Fenomenología de la percepción, Maurice Merleau-Ponty, ed., 115-164. Buenos Aires: Planeta Agostini.

MoniÑo, Ignacio

2004 «Cambio musical, devoción y procesos sociales: análisis etnomusicológico de la procesión de Bandas de Sikuris del Abra de Punta Corral». Ponencia presentada en las Segundas Jornadas de Investigación en Antropología Social, 5-6 de agosto de 2004, Facultad de Filosofía y Letras, Universidad de Buenos Aires.

NietzSChe, Friedich

1972 Así habló Zaratustra. Madrid: Alianza.

Ramos Gavilán, Alonso

1976 Historia de Nuestra Señora de Copacabana. La Paz: Academia Boliviana de la Historia - Cámara Nacional de Comercio - Cámara Nacional de Industrias.

Ros, Agustí

2009 «Laban Movement Analysis (Una herramienta para la teoría y la práctica del movimiento)». Estudis Escènics 35: 350-357.

VEGA, María Alejandra

2012 «Una aproximación a la música de las bandas de sikus en Tilcara y Buenos Aires». Ponencia presentada en la Jornada de la Música y la Musicología, Jornadas Interdisciplinarias de Investigación, IX, 9-11 octubre 2012. Buenos Aires: Universidad Católica Argentina. Documento electrónico, http://bibliotecadigital.uca.edu.ar/repositorio/ponencias/aproximacion-musica-bandas-sikus-tilcara.pdf, con acceso el $10 / 12 / 2014$.

Zanolli, Carlos, Julia Costilla y Dolores Estruch

2010 «Cofrades, esclavos y devotos. La peregrinación al Santuario de la Virgen de Copacabna de Punta Corral. Jujuy, Argentina», en Patrimonio Cultural Inmaterial Latinoamericano-Fiestas, pp. 9-40. Cusco: Crespial. 